Check for updates

Cite this: RSC Adv., 2019, 9, 34430

Received 16th August 2019

Accepted 14th October 2019

DOI: 10.1039/c9ra06402h

rsc.li/rsc-advances

\section{Diphenyl polysulfides: cathodes with excellent lithiation performance and high specific energy for LSBs†}

\begin{abstract}
Chang Wang, ${ }^{a}$ Jianbao Wu, (D) *a Xiaoyi Li ${ }^{a}$ and Yiming Mi ${ }^{\mathrm{b}}$
Reversible lithium-sulfur batteries (LSBs) are considered one of the most promising next-generation energy storage systems. However, the shuttling effect of lithium polysulfide significantly weakens the electrochemical properties and the cycle life, hindering its practical application. Organo-sulfides are unique materials with low cost, profuse content and high capacity. Here, via quantum chemical calculations, we introduce a class of diphenyl polysulfides, $\mathrm{PhS}_{n} \mathrm{Ph}(2 \leq n \leq 15)$, which are all structurally stable, confirmed by calculation of their Gibbs free energies. The theoretical specific energy of $\mathrm{PhS}_{15} \mathrm{Ph}$ is high, up to $2632 \mathrm{~W} \mathrm{~h} \mathrm{~kg}^{-1}$, exceeding that of $\mathrm{S}_{8}$. By calculating the bond dissociation energy of $\mathrm{S}-\mathrm{S}$ in $\mathrm{PhS}_{n} \mathrm{Ph}$ molecules, we analyze the breaking processes of the $\mathrm{S}-\mathrm{S}$ bonds in each step of lithiation. The microscopic mechanism of the fast reaction kinetics of $\mathrm{PhS}_{n} \mathrm{Ph}$ cathodes is explored. It is phenyl that prevents the formation of soluble long-chain polysulfide molecules $\left(\mathrm{Li}_{2} \mathrm{~S}_{4}, \mathrm{Li}_{2} \mathrm{~S}_{6}, \mathrm{Li}_{2} \mathrm{~S}_{8}\right)$ in the lithiation process, efficiently weakening the "shuttle effect".
\end{abstract}

\section{Introduction}

Compared with traditional lithium ion secondary batteries, rechargeable lithium sulfur batteries (LSBs) are widely considered an ideal choice for electric vehicles due to their high theoretical specific capacity and specific energy. ${ }^{1}$ However, many problems and challenges limit the application of LSBs. One of the most important problems is the "shuttle effect".,3 The capacity attenuation, ${ }^{4}$ low coulomb efficiency ${ }^{5}$ and high self-discharge rate ${ }^{6}$ caused by the "shuttle effect" restrict the practical application of LSBs. ${ }^{7}$ Inhibiting the shuttling of polysulfide is the key to the development of $\mathrm{Li}-\mathrm{S}$ batteries for excellent electrochemical properties. ${ }^{8}$ Extensive efforts have been made to improve it., ${ }^{9010}$ Amruth Bhargav et al. ${ }^{11}$ used CNTs as the porous and conductive carbon matrix to efficiently trap soluble polysulfides. Liang X. et al. ${ }^{12}$ synthetized sulfur/ manganese dioxide nanosheet composite which can entrap polysulfides in the cathode. Tae-Gyung Jeong et al..$^{13}$ encapsulated sulfur particles with functional polymers, which enhanced the cycling stability by suppressing the dissolution of polysulfide from the sulfur materials and rendered the electrodes less reactive toward liquid electrolyte. Jing Zheng et al. ${ }^{14}$

${ }^{a}$ School of Mathematics, Physics and Statistics, Shanghai University of Engineering Science, 333 Longtong Road, Shanghai 201620, China. E-mail: wujianbao@sues. edu.cn

${ }^{b}$ College of Chemistry and Chemical Engineering, Shanghai University of Engineering Science, 333 Longtong Road, Shanghai 201620, China

$\dagger$ Electronic supplementary information (ESI) available. See DOI: $10.1039 / \mathrm{c} 9 \mathrm{ra} 06402 \mathrm{~h}$ proposed a new kind of localized high-concentration electrolyte. It achieved a high coulombic efficiency up to $99.3 \%$ and completely suppressing the shuttling effect. Tianyu Lei et al. ${ }^{15}$ synthesized PAN@APP microfiber separator to bind interaction with polysulfides strongly and improve the safety.

Recently, an excellent cathode material with high cyclic stability and energy efficiency has been studied by Min Wu et al. ${ }^{16}$ They compounded $\mathrm{PhS}_{3} \mathrm{Ph}$ with the $\mathrm{PhS}_{2} \mathrm{Ph}$ and $\mathrm{S}_{8}$. The cell delivers an initial discharge specific energy of $751 \mathrm{~W} \mathrm{~h} \mathrm{~kg}^{-1}$ with high energy efficiency. Then, Amruth Bhargav et al. ${ }^{17}$ introduced a new class of phenyl polysulfides $\mathrm{PhS}_{n} \mathrm{Ph}(4 \leq x \leq$ 6) as liquid cathode materials. Their volume change when reduced is about $37 \%$ and $\mathrm{PhS}_{6} \mathrm{Ph}$ can provide a specific energy of $1665 \mathrm{~W} \mathrm{~h} \mathrm{~kg}^{-1}$. Therefore, increasing the number of $\mathrm{S}$ atoms in polysulfide diphenyl could improve the specific capacity of LSBs. Wei Chen et al. ${ }^{18}$ achieved a cathode with high rate and stable cycling performance by increasing sulfur content.

In this paper, we investigate the stability $\mathrm{PhS}_{n} \mathrm{Ph}(2 \leq n \leq 15)$ molecules by density functional theory calculation. According to the calculation results, the sulfur atoms in the $\mathrm{PhS}_{n} \mathrm{Ph}$ molecules behave chain-like spiral distribution between two phenyl groups, the structure of $\mathrm{PhS}_{n} \mathrm{Ph}$ molecules are stable by analyzing the formation of Gibbs free energy. More importantly, the specific energy of $\mathrm{PhS}_{15} \mathrm{Ph}$ is up to $2632 \mathrm{~W} \mathrm{~h} \mathrm{~kg}^{-1}$, very close to the theoretical value of $\mathrm{S}_{8}$. Furthermore, we analyze the lithiation process of the $\mathrm{PhS}_{n} \mathrm{Ph}$ cathodes by calculating the bond dissociation energies of S-S bonds in the $\mathrm{PhS}_{n} \mathrm{Ph}$ molecules. The calculating results reveal a new kind of inhibition mechanism of "shuttle effect". In the lithiation process, as an intermediate lithiation product, the long chain $\mathrm{PhS}_{n} \mathrm{Li}$ has 
excellent structural stability after phenyls are added as small electrophilic groups. The final lithiation products are PhSLi, $\mathrm{Li}_{2} \mathrm{~S}$ and $\mathrm{Li}_{2} \mathrm{~S}_{2}$. There's no $\mathrm{Li}_{2} \mathrm{~S}_{n}(n=4,6,8)$ molecules being introduced in the whole discharge process, which are the major factor for the generating "shuttle effect". In the experiment, the $\mathrm{PhS}_{n} \mathrm{Ph}(2 \leq n \leq 6)$ have been synthesized successfully, ${ }^{16,17}$ the $\mathrm{PhS}_{n} \mathrm{Ph}(7 \leq n \leq 15)$ with more $\mathrm{S}$ atoms are confirmed to be thermodynamically stable by the analysis of "alloy-like" diagrams. ${ }^{19}$ Considering elemental abundance ${ }^{20}$ and scalability of synthetic methods, the LSBs with $\mathrm{PhS}_{n} \mathrm{Ph}$ as cathodes also may surpass lithium-ion battery as a electrochemical storage system. ${ }^{21}$ Therefore, this class of polysulfides could be a kind of promising high-capacity cathode material for LSBs.

\section{Computational methods}

All the calculations of Gibbs free energies presented in this paper were performed using the Gaussian 16 code. The polarizable continuum model (PCM) ${ }^{22}$ was used to describe the interaction between $\mathrm{PhS}_{n} \mathrm{Ph} / \mathrm{PhS}_{n} \mathrm{Li}$ and the electrolyte. The fully optimization of geometries, Gibbs free energies, bond dissociation energy (BDE) and vibrational frequency were performed by the B3LYP/6-311+G(d) DFT functional and basis set, which were widely used to calculate the organo-sulfides. ${ }^{23}$ The electronic excitation energies were calculated at the TD-B3LYP/ 6-311+G(d) level of theory. Gaussian band-shapes with a bandwidth of $0.2 \mathrm{eV}$ (two thousand wavenumbers) were used to simulate the UV-vis spectra.

In order to confirm the possibility of adding more sulfur atoms between two phenyls, here we make an "alloy-like" diagram $^{19}$ to analyze the possibility. The Gibbs free energy difference $(\Delta G)$ is used to analyze the relative stability and reaction feasibility of $\mathrm{PhS}_{n} \mathrm{Ph}$, the formation energies are defined as:

$$
G_{\text {form }}=\left[G_{\mathrm{PhS}_{n} \mathrm{Ph}}-\frac{1}{8}(n-2) G_{\mathrm{S}_{8}}-G_{\mathrm{PhS}_{2} \mathrm{Ph}}\right] /(n-1)
$$

As shown in Fig. 1, when $n=0,1$, they stand for the reactant $\mathrm{PhS}_{2} \mathrm{Ph}$ and $\mathrm{S}_{8}$, respectively, the $G_{\text {form }}$ equals zero. It can be seen that all of $G_{\text {form }}$ are negative. As the number of S increases, $G_{\text {form }}$ decreases with the number of $\mathrm{S}$ atoms increasing, indicating that more sulfur atom could be added between two phenyls. The advantage of "alloy-like" diagram is to see whether a particular compound is thermodynamically stable. If one compound is above the convex hull, it will be unstable, and will decompose into the two nearby compounds. Judging by the results shown in Fig. 1, all the diphenyl polysulfides are thermodynamically stable.

\section{Results and discussion}

\section{1 $\mathrm{PhS}_{n} \mathrm{Ph}$ molecules}

Firstly, the structures of $\mathrm{PhS}_{n} \mathrm{Ph}$ molecules are optimized without considering the solvent effect. After completely optimized, phenyl groups are at both ends, and sulfur atoms are chain-like between the two phenyl groups. The bond lengths, bond angles of $\mathrm{S}-\mathrm{S}$ bonds and $\mathrm{S}-\mathrm{Ph}$ bonds, and dihedral angles of phenyls are listed in Table 1 . The S-S bond lengths are in the interval of 2.04-2.09 $\AA$ and the interval of bond angles of S-S bonds are 107.48-110.26 , which in good agreement with the literature of Ralf Steude's review about the chain-like structures of $\mathrm{RS}_{n} \mathrm{R}$ molecules. ${ }^{24}$ In Fig. 1, we show the optimized structural configures of $\mathrm{PhS}_{n} \mathrm{Ph}$ molecules, the $\mathrm{S}-\mathrm{S}$ bonds between two benzene ring screw around in the range of $320-330^{\circ}$, close to $360^{\circ}$, so the two phenyl groups nearly symmetric at $n=3,6,9,12$. This feature can also be verified from the dihedral angles. The dihedral angles of $\mathrm{PhS}_{3} \mathrm{Ph}, \mathrm{PhS}_{6} \mathrm{Ph}, \mathrm{PhS}_{9} \mathrm{Ph}, \mathrm{PhS}_{12} \mathrm{Ph}$ are smaller, which are $1.38^{\circ}, 40.32^{\circ}, 26.74^{\circ}$ and $16.77^{\circ}$, respectively.

To compare some useful information with in situ and operando experiments, we simulated ultraviolet-visible (UVvis) spectroscopy. As shown in Fig. 2(a), there is only one peak among the ultraviolet range $(200-700 \mathrm{~nm})$ for different phenyl polysulfides; the peak wavelength $(\lambda$, in $\mathrm{nm})$ increase

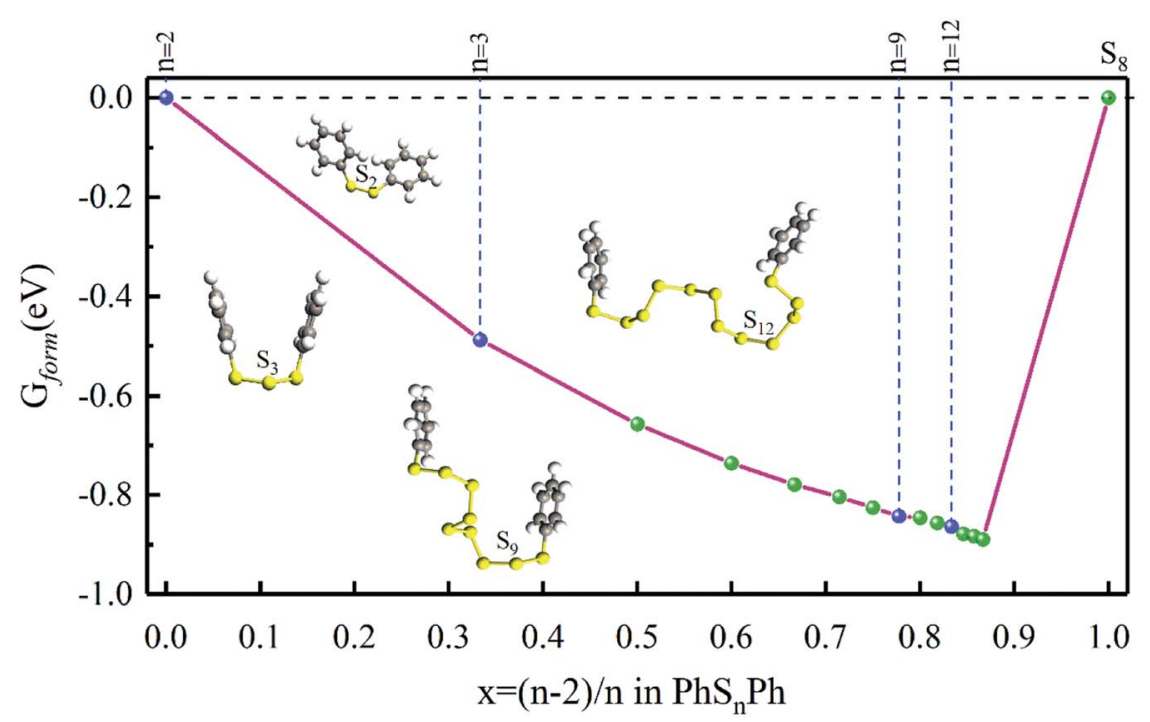

Fig. 1 The $G_{\text {form }}$ for $\mathrm{PhS}_{n} \mathrm{Ph}(1 \leq n \leq 15)$, the inset show the optimized stable structures of $\mathrm{PhSPh}, \mathrm{PhS}_{2} \mathrm{Ph}, \mathrm{PhS}_{3} \mathrm{Ph}, \mathrm{PhS} 9 \mathrm{Ph}$ and $\mathrm{PhS}{ }_{12} \mathrm{Ph}$, respectively. 
Table 1 The bond lengths, bond angles and dihedral angles of $\mathrm{PhS}_{n} \mathrm{Ph}(1 \leq n \leq 12)$

\begin{tabular}{|c|c|c|c|c|c|}
\hline & $\begin{array}{l}\text { Bond length } \\
d_{\mathrm{SS}}(\AA)\end{array}$ & $\begin{array}{l}\text { Bond angle } \\
\alpha_{\mathrm{SsS}}(\mathrm{deg})\end{array}$ & $\begin{array}{l}\text { Dihedral angle } \\
\gamma_{\mathrm{Ph}}(\mathrm{deg})\end{array}$ & $\begin{array}{l}\text { Bond length } \\
d_{\mathrm{SPh}}(\AA)\end{array}$ & $\begin{array}{l}\text { Bond angle } \\
\alpha_{\mathrm{SSPh}}(\mathrm{deg})\end{array}$ \\
\hline $\mathrm{PhSPh}$ & - & - & 3.36 & 1.78 & 140.37 \\
\hline $\mathrm{PhS}_{3} \mathrm{Ph}$ & $2.07-2.08$ & 109.75 & 1.38 & 1.79 & $105.56-106.25$ \\
\hline $\mathrm{PhS}_{4} \mathrm{Ph}$ & 2.08 & $109.12-109.29$ & 77.14 & 1.78 & 104.64-105.04 \\
\hline $\mathrm{PhS}_{5} \mathrm{Ph}$ & $2.07-2.08$ & $108.62-108.64$ & 128.76 & 1.78 & $104.55-105.31$ \\
\hline $\mathrm{PhS}_{8} \mathrm{Ph}$ & $2.07-2.09$ & $107.88-109.63$ & 146.72 & 1.78 & $104.76-105.70$ \\
\hline $\mathrm{PhS}_{9} \mathrm{Ph}$ & $2.07-2.08$ & 108.01-109.19 & 26.74 & 1.78 & 104.69-105.12 \\
\hline $\mathrm{PhS}_{10} \mathrm{Ph}$ & $2.07-2.09$ & $107.78-110.26$ & 136.86 & 1.78 & $105.08-107.20$ \\
\hline $\mathrm{PhS}_{11} \mathrm{Ph}$ & $2.07-2.09$ & $107.51-110.15$ & 80.13 & 1.78 & $104.75-105.13$ \\
\hline $\mathrm{PhS}_{12} \mathrm{Ph}$ & $2.07-2.09$ & $107.48-110.07$ & 16.77 & 1.78 & 104.67-105.05 \\
\hline
\end{tabular}

with the number of $\mathrm{S}$ atom $(n)$ and convergence at the $\mathrm{PhS}_{6} \mathrm{Ph}$. Only considering the $\mathrm{PhS}_{2} \mathrm{Ph}, \mathrm{PhS}_{4} \mathrm{Ph}, \mathrm{PhS}_{5} \mathrm{Ph}$ and $\mathrm{PhS}_{6} \mathrm{Ph}$, the curve of peak $\lambda$ behave almost linear strand, which is in good agree with the experiment dates. ${ }^{17}$ When $n$ (number of sulfur atoms) is an integer multiple of $3(n=3,6,9$ and 12), the peak $\lambda$ behaves a bigger bathochromic shift which are shown with red dots in Fig. 2(b). The peak wavelengths are derived from the out-of-plane deformation of the phenyl rings due to the polysulfide linkages. ${ }^{25}$ According to the structure configures shown in inset Fig. 1, the sulfur atoms between two phenyls are chain-like and present a spiral, three sulfur atoms form a unit; when there are integer units in the linkages $(n=3,6,9$ and 12), the dihedral angles are smaller, the structure configures of $\mathrm{PhS}_{3} \mathrm{Ph}, \mathrm{PhS}_{6} \mathrm{Ph}, \mathrm{PhS}_{9} \mathrm{Ph}, \mathrm{PhS}_{12} \mathrm{Ph}$ show more symmetric and behave more stable. The characteristics of the above-mentioned UV-vis spectroscopy of $\mathrm{PhS}_{n} \mathrm{Ph}$ could be used to identify the synthesized polysulfides in experiments.

\subsection{Average voltage and specific energy of $\mathrm{PhS}_{n} \mathrm{Ph}$ cathodes}

In order to calculate the average voltages of $\mathrm{PhS}_{n} \mathrm{Ph}$ cathodes, the implicit solvent model (PCM) was used to describe the interaction between $\mathrm{PhS}_{n} \mathrm{Ph}$ and the electrolyte. Both in experiment $^{26}$ and calculation, ${ }^{27}$ 1,2-dimethoxyethane (DME) and 1,3dioxolane (DOL) are the electrolytes widely used in lithiumsulfur batteries at present. With DME/DOL $(1: 1, v / v)$, the theoretical voltage of polysulfides is quite close to the experimental voltage of $2.0-2.6 \mathrm{~V}^{28,29}$ Therefore, in the following research, all calculation consider solvation effect of DME/DOL $(1: 1, \mathrm{v} / \mathrm{v})$ to make our results more reasonable and close to reality. We calculate average voltages according to the average energy changes of full lithiation processes. ${ }^{30}$ The process of full lithiation can be expressed as:

$$
\mathrm{PhS}_{n} \mathrm{Ph}+(2 n-2) \mathrm{Li}=2 \mathrm{PhSLi}+(n-2) \mathrm{Li}_{2} \mathrm{~S}
$$

the average free energy change per step of lithiation is:

$$
\begin{aligned}
G_{\mathrm{ave}} & =\left[2 G_{\mathrm{PhSLi}}+(n-2) G_{\mathrm{Li}_{2} \mathrm{~S}}-G_{\mathrm{PhS}_{n} \mathrm{Ph}}\right. \\
& \left.-(2 n-2) G_{\mathrm{Li}}\right] /(2 n-2)
\end{aligned}
$$

Note that, not existing originally in the anode, the Gibbs free energy here for $\mathrm{Li}$ is electrolyte-free. The average voltages of $\mathrm{PhS}_{n} \mathrm{Ph}$ cathodes are shown in Fig. 3, as well as the discharge specific capacity and specific energy.

From Fig. 3, the average voltages first reduce quickly as $n$ increases in $\mathrm{PhS}_{n} \mathrm{Ph}$, and then approach to $2.227 \mathrm{~V}$ when $n \geq 9$. Next, we analyze the discharge specific capacities and specific energies. With the increasing of $\mathrm{S}$ atoms, they keep rising. The specific energy of $\mathrm{PhS}_{15} \mathrm{Ph}, 2632 \mathrm{~W} \mathrm{~h} \mathrm{~kg}{ }^{-1}$, reaches the theoretical value of $\mathrm{S}_{8}, 2600 \mathrm{~W} \mathrm{~h} \mathrm{~kg}{ }^{-1} \cdot{ }^{31}$ And its specific capacity is

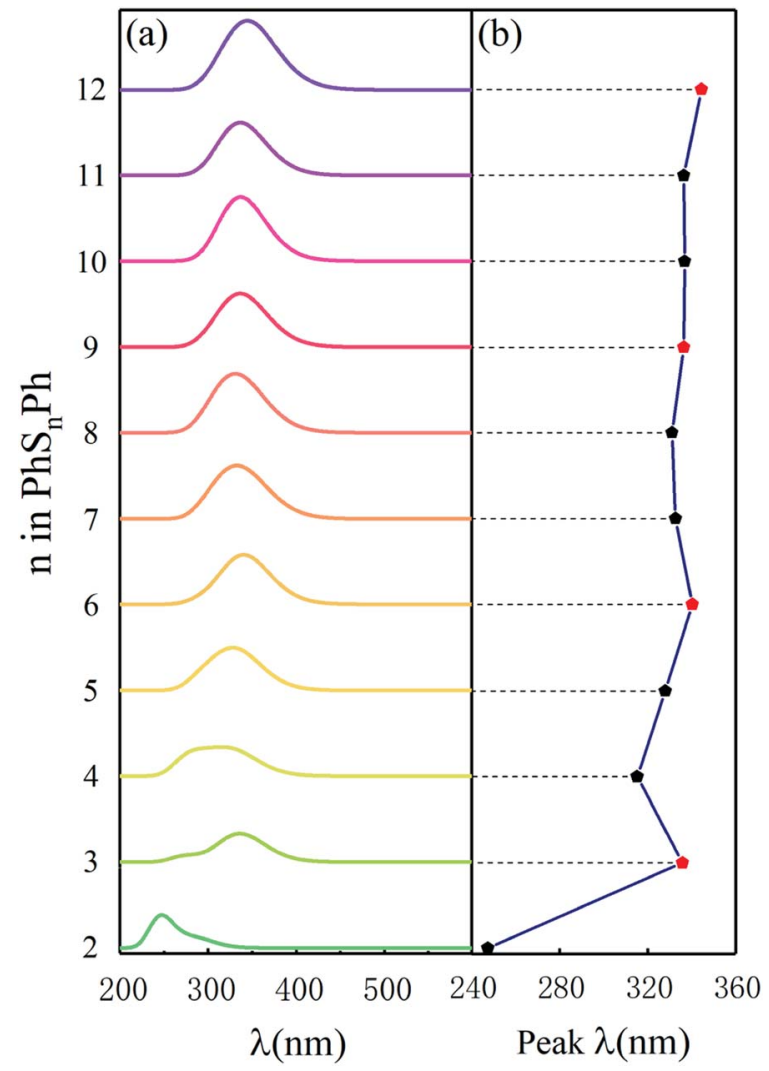

Fig. 2 (a) Simulated UV-vis spectra and (b) the peak $\lambda$ in UV-vis spectra of the $\mathrm{PhS}_{n} \mathrm{Ph}(2 \leq n \leq 12)$ molecules. 


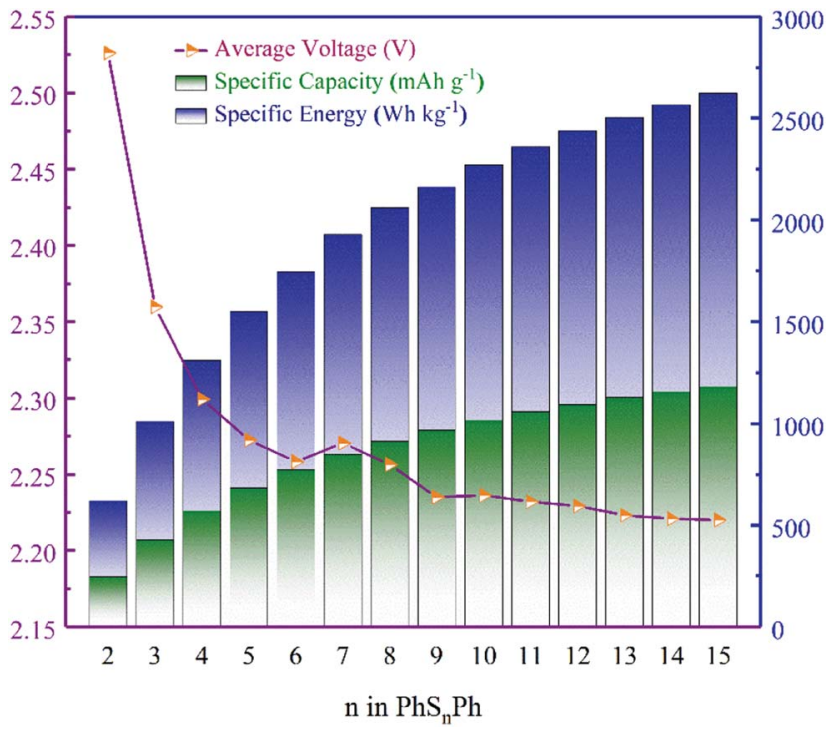

Fig. 3 The average voltages, specific capacities and specific energies of the $\mathrm{PhS}_{n} \mathrm{Ph}$ cathode.

up to $1182 \mathrm{~mA} \mathrm{~h} \mathrm{~g}{ }^{-1}$, nearly five times that of state-of-the-art cathode materials used in Li-ion batteries. ${ }^{32}$ The comparison of theoretical specific capacities and energies clearly indicate the great promise $\mathrm{PhS}_{n} \mathrm{Ph}$ hold in surpassing the current cathode materials used in Li-ion batteries.

\subsection{The discharge lithiation process of $\mathrm{PhS}_{n} \mathrm{Ph}$ cathodes}

Here we propose the bond dissociation energy (BDE) as another method to analysis the lithiation. BDE, also called bond dissociation enthalpy, is the most effective quantitative description of chemical bonds, ${ }^{33}$ It is defined as the change in reaction enthalpy of the breaking process of chemical bonds, that is, BDEs are investigated by the density functional theory. ${ }^{34}$ In this way, DFT can predict excellent results for these energies. ${ }^{35}$ The sum of electronic and thermal enthalpies of $\mathrm{PhS}_{n} \mathrm{Ph}, \mathrm{PhS}_{x}^{\cdot}$ and $\mathrm{PhS}_{n-x}^{\cdot}$ are calculated to determine the dissociation energies of the bonds. BDEs are all positive because the bonds need to absorb energies to dissociate. In other words, it's easier for bonds to break where the dissociation energy is lower. M. J. Bausch et al. has estimated S-S $\mathrm{BDE}$ of phenyl disulfide. Literature data indicates that the gasphase BDE for the S-S bonds in PhSSPh is about $55 \mathrm{kcal} \mathrm{mol}^{-1}$, $2.31 \mathrm{eV}^{36}$ With the method above, $\mathrm{S}-\mathrm{S}$ BDE of $\mathrm{PhS}_{2} \mathrm{Ph}$ in DME/ DOL $(1: 1, \mathrm{v} / \mathrm{v})$ is $2.46 \mathrm{eV}$. It is a little bigger than that of gasphase because of different states. But they are very consistent and enough to demonstrate that our calculation is reliable.

According to Fig. 4, the first step of lithiation may react at the second S-S bond or the penultimate one, which can be described equally as:

$$
\mathrm{PhS}_{n} \mathrm{Ph}=\mathrm{PhS}_{2}^{\cdot}+\mathrm{PhS}_{n-2}^{\cdot}
$$

What is more, it could be that both of the two bonds break at the same time:

$$
\mathrm{PhS}_{n} \mathrm{Ph}=2 \mathrm{PhS}_{2}^{\cdot}+\cdot \mathrm{S}_{n-4}^{\cdot}
$$

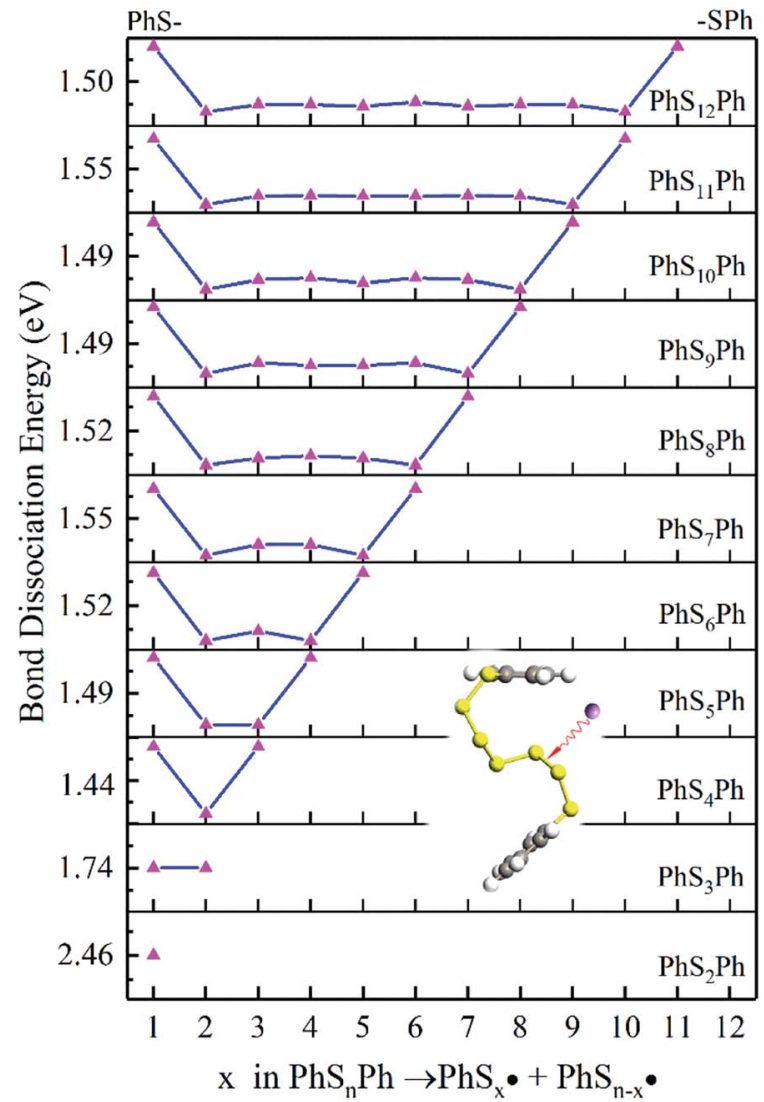

Fig. 4 The $\mathrm{BDE}$ of $\mathrm{S}-\mathrm{S}$ bonds in the $\mathrm{PhS}_{n} \mathrm{Ph}$. The inset shows the breaking position in $\mathrm{PhS}_{6} \mathrm{Ph}$.

In judging the strength of a bond in a chemical reaction, we should also consider the stability of free radicals after dissociation. Since the free radicals would directly generate $\mathrm{PhS}_{n} \mathrm{Li}$ with $\mathrm{Li}^{+}$, the stability of the $\mathrm{PhS}_{x}^{*}$ can be measured by the Gibbs formation energies of $\mathrm{PhS}_{n} \mathrm{Li}$. We also use an "alloy-like" diagram to analyze the optimized molecules. We get the formation energies based on this equation:

$$
G_{\text {form }}=\left[G_{\mathrm{PhS}_{n} \mathrm{Li}}-(n-1) G_{\mathrm{S}_{8}} / 8-G_{\mathrm{PhSLi}}\right] / n
$$

As it is shown in Fig. 5, long-chain $\mathrm{PhS}_{n} \mathrm{Li}(n \geq 3)$ is more stable than $\mathrm{PhS}_{2} \mathrm{Li}$ with lower Gibbs formation energy. So in the first step of lithiation, only one bond would dissociate to form $\mathrm{PhS}_{2} \mathrm{Li}$ and $\mathrm{PhS}_{n-2} \mathrm{Li}$. Concern is that there is no $\mathrm{Li}_{2} \mathrm{~S}_{n}$ in this reaction:

$$
\mathrm{PhS}_{n} \mathrm{Ph}+2 \mathrm{Li}=\mathrm{PhS}_{2} \mathrm{Li}+\mathrm{PhS}_{n-2} \mathrm{Li}
$$

We use the same ways to analysis the subsequent lithiation of $\mathrm{PhS}_{n} \mathrm{Li}$, shown in Fig. 6. The lower position of dissociation energy of S-S bond increases with the increase of $n$. But considering better stability of long-chain $\mathrm{PhS}_{n} \mathrm{Li}(n \geq 3)$, the lithiation of $\mathrm{PhS}_{n} \mathrm{Li}$ would react at the penultimate S-S bond to generate $\mathrm{PhS}_{n-2} \mathrm{Li}$ and $\mathrm{Li}_{2} \mathrm{~S}_{2}(n \geq 3)$ or $\mathrm{Li}_{2} \mathrm{~S}(n=2)$. The latter lithiations will follow this pattern until they are completely reduced into PhSLi and $\mathrm{Li}_{2} \mathrm{~S}$. 


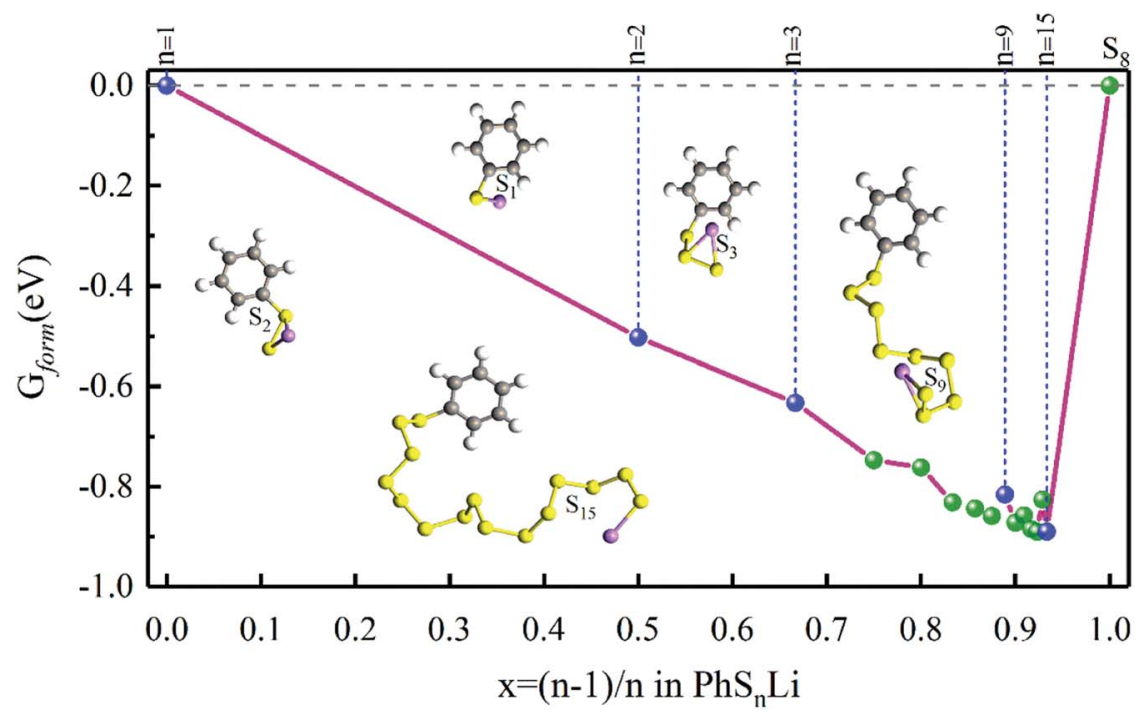

Fig. 5 The $G_{\text {form }}$ for $\mathrm{PhS}_{n} \mathrm{Li}$. The insets show the optimized stable structures of PhSLi, PhS 2 Li, PhS 3 Li, PhS 9 Li and PhS ${ }_{15} L i$, respectively.

In conclusion, at the beginning of the discharge, $\mathrm{PhS}_{n} \mathrm{Ph}$ is reduced to $\mathrm{PhS}_{2} \mathrm{Li}$ and $\mathrm{PhS}_{n-2} \mathrm{Li}$. With the depth of discharge increasing, $\mathrm{PhS}_{n-4} \mathrm{Ph}, \mathrm{PhS}_{n-6} \mathrm{Ph}, \mathrm{PhS}_{n-8} \mathrm{Ph}$ and other intermediate products $\left(\mathrm{PhS}_{x} \mathrm{Li}\right)$ are generated in sequence. Meanwhile, $\mathrm{Li}_{2} \mathrm{~S}_{2}$ is formed. Finally, $\mathrm{PhS}_{2} \mathrm{Li}$ is further reduced to PhSLi and $\mathrm{Li}_{2} \mathrm{~S}$. $\mathrm{Li}_{2} \mathrm{~S}_{2}$ is deoxidized into $\mathrm{Li}_{2} \mathrm{~S}$. This chemical change can be expressed by four steps:

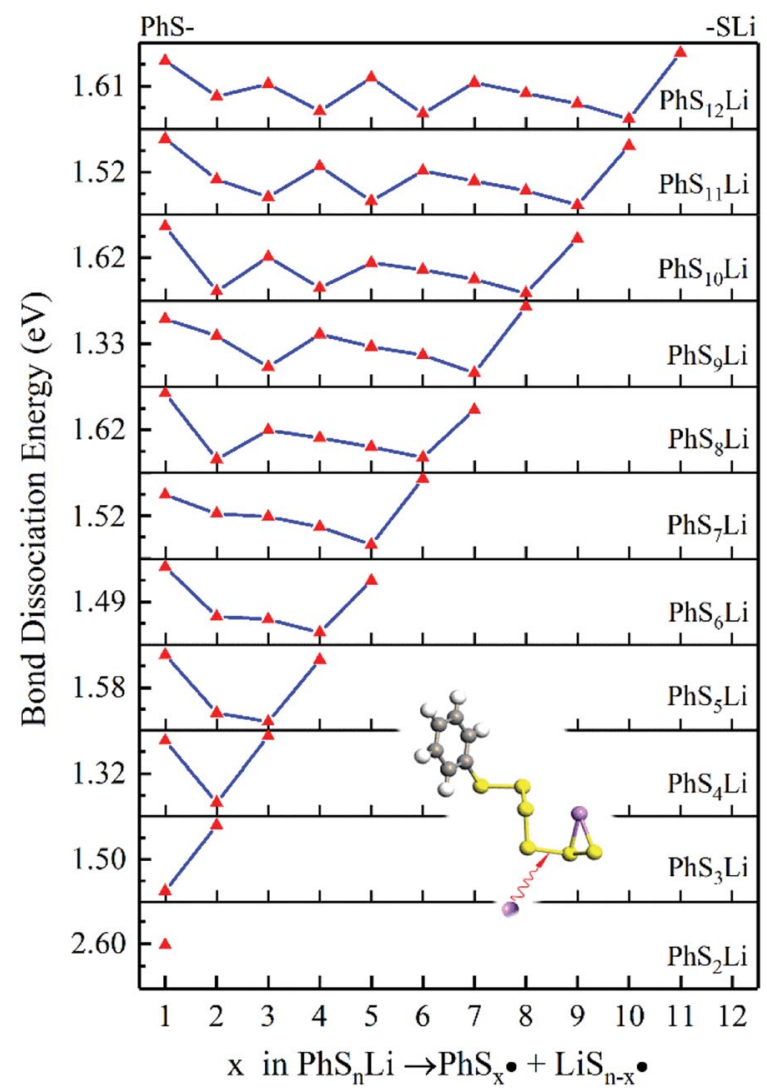

Fig. 6 The BDE of S-S bonds of $\mathrm{PhS}_{n} \mathrm{Li}$. The inset shows the breaking position of $\mathrm{PhS}_{6} \mathrm{Li}$.

$$
\begin{gathered}
\mathrm{PhS}_{n} \mathrm{Ph}+2 \mathrm{Li}=\mathrm{PhS}_{2} \mathrm{Li}+\mathrm{PhS}_{n-2} \mathrm{Li} \\
\mathrm{PhS}_{x} \mathrm{Li}+2 \mathrm{Li}=\mathrm{PhS}_{x-2} \mathrm{Li}+\mathrm{Li}_{2} \mathrm{~S}_{2} \\
\mathrm{PhS}_{2} \mathrm{Li}+2 \mathrm{Li}=\mathrm{PhSLi}+\mathrm{Li}_{2} \mathrm{~S} \\
\mathrm{Li}_{2} \mathrm{~S}_{2}+2 \mathrm{Li}=2 \mathrm{Li}_{2} \mathrm{~S}
\end{gathered}
$$

In this discharge sequence, the reaction energies $\left(G_{\text {rec }}\right)$ can be calculated with the energy difference between the reactants and the products. Based on reaction energies, the corresponding voltages versus $\mathrm{Li}_{/} \mathrm{Li}^{+}$are listed in Table $\mathrm{S} 1 . \dagger$ Fig. 7(a) shows calculated reaction sequences of $\mathrm{PhS}_{5} \mathrm{Ph}$. $\mathrm{PhS}_{5} \mathrm{Ph}$ may break the S-S bond and form $\mathrm{PhS}_{3} \mathrm{Li}$ and $\mathrm{PhS}_{2} \mathrm{Li}$ when attracted by $\mathrm{Li}^{+}$and $\mathrm{e}^{-}$firstly. During the step of discharge, the reaction energy is $5.05 \mathrm{eV}$ and the voltage is $2.53 \mathrm{~V}$. Then $\mathrm{PhS}_{3} \mathrm{Li}$ will take another $\mathrm{Li}^{+}$ and $\mathrm{e}^{-}$to generate $\mathrm{PhS}_{2} \mathrm{Li}$ with $2.52 \mathrm{~V}$. The final step is that $\mathrm{PhS}_{2} \mathrm{Li}$ and $\mathrm{Li}_{2} \mathrm{~S}_{2}$ are reduced into PhSLi and $\mathrm{Li}_{2} \mathrm{~S}$, respectively. The two reactions can be regarded as the final step of the whole lithiation and the average voltage is $2.04 \mathrm{~V}$. The voltage profiles of the entire discharge process are mostly consistent with the experiments. ${ }^{17}$

To reveal the structure change of $\mathrm{PhS}_{n} \mathrm{Ph}$ when attacked by $\mathrm{a} \mathrm{Li}^{+}$and a e ${ }^{-}$, we take $\mathrm{PhS}_{5} \mathrm{Ph}$ for example to draw the difference map of electron density. In Fig. 7(b), red solid lines and blue dashed lines correspond to the regions having increased electron density and decreased electron density during the process, respectively. Obviously, the $S_{2}-S_{3}$ bond is weakened sharply and the $\mathrm{Li}^{+}$is bonded to $\mathrm{S}_{3}$. Furthermore, the $\mathrm{S}_{2}-\mathrm{S}_{3}$ bond distance increase from $2.08 \AA$ to $3.19 \AA$. $\mathrm{PhS}_{5} \mathrm{Ph}$ molecule splits up to form $\mathrm{PhS}_{3} \mathrm{Li}$ and $\mathrm{PhS}_{2}^{*}$ radical, the latter of which will further obtain a $\mathrm{Li}^{+}$and a $\mathrm{e}^{-}$to form $\mathrm{PhS}_{2} \mathrm{Li}$. The result is the same with the first lithiation step derived from BDE. For this reason, it also proves that our method of analyzing the lithiation steps by BDE is reliable.

The discharge order of $\mathrm{PhS}_{10} \mathrm{Ph}$ is shown in Table 2. In the first step, $\mathrm{PhS}_{10} \mathrm{Ph}$ is reduced to $\mathrm{PhS}_{2} \mathrm{Li}$ and $\mathrm{PhS}_{8} \mathrm{Li}$ at $2.68 \mathrm{~V}$. As the discharge depth increases, $\mathrm{PhS}_{8} \mathrm{Li}$ is reduced to $\mathrm{PhS}_{6} \mathrm{Li}$, $\mathrm{PhS}_{4} \mathrm{Li}$ and $\mathrm{PhS}_{2} \mathrm{Li}$ in sequence with voltages of $2.52 \mathrm{~V}, 2.46 \mathrm{~V}$ 

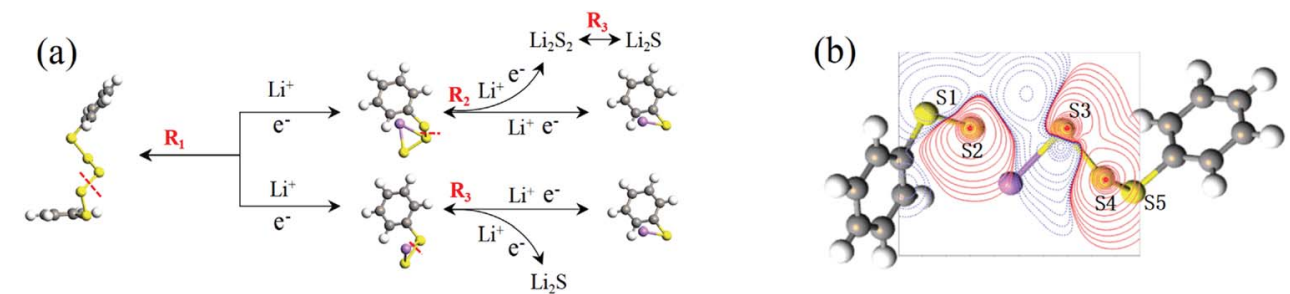

Fig. 7 (a) Schematic illustration of the discharge process of the $\mathrm{PhS}_{5} \mathrm{Ph}$ cathode; (b) relaxed structure of $\mathrm{PhS}{ }_{5} \mathrm{Ph}+\mathrm{Li}$, the difference map of electron density between $\mathrm{S}$ and $\mathrm{Li}$ are also shown.

Table 2 The discharge reactions, reaction energies and corresponding voltages of $\mathrm{PhS}_{5} \mathrm{Ph}$ and $\mathrm{PhS}_{10} \mathrm{Ph}$

\begin{tabular}{|c|c|c|c|c|c|}
\hline $\mathrm{R}_{1}$ & $\mathrm{PhS}_{5} \mathrm{Ph}$ & $\mathrm{PhS}_{5} \mathrm{Ph}+2 \mathrm{Li}=\mathrm{PhS}_{2} \mathrm{Li}+\mathrm{PhS}_{3} \mathrm{Li}$ & -5.05 & 2.53 & $\checkmark$ \\
\hline $\mathrm{R}_{2}$ & & $\mathrm{PhS}_{3} \mathrm{Li}+2 \mathrm{Li}=\mathrm{PhSLi}+\mathrm{Li}_{2} \mathrm{~S}_{2}$ & -5.03 & 2.52 & $\checkmark$ \\
\hline $\mathrm{R}_{3}$ & & $\mathrm{Li}_{2} \mathrm{~S}_{2}+2 \mathrm{Li}=2 \mathrm{Li}_{2} \mathrm{~S}$ & -3.80 & 1.90 & $\checkmark$ \\
\hline $\mathrm{R}_{1}$ & $\mathrm{PhS}_{10} \mathrm{Ph}$ & $\mathrm{PhS}_{10} \mathrm{Ph}+2 \mathrm{Li}=\mathrm{PhS}_{2} \mathrm{Li}+\mathrm{PhS}_{8} \mathrm{Li}$ & -5.36 & 2.68 & $\checkmark$ \\
\hline $\mathrm{R}_{2}$ & & $\mathrm{PhS}_{8} \mathrm{Li}+2 \mathrm{Li}=\mathrm{PhS}_{6} \mathrm{Li}+\mathrm{Li}_{2} \mathrm{~S}_{2}$ & -5.04 & 2.52 & $\checkmark$ \\
\hline $\mathrm{R}_{3}$ & & $\mathrm{PhS}_{2} \mathrm{Li}+2 \mathrm{Li}=\mathrm{PhSLi}+\mathrm{Li}_{2} \mathrm{~S}$ & -4.36 & 2.18 & $\checkmark$ \\
\hline $\mathrm{R}_{3}$ & & $\mathrm{Li}_{2} \mathrm{~S}_{2}+2 \mathrm{Li}=2 \mathrm{Li}_{2} \mathrm{~S}$ & -3.80 & 1.90 & $\checkmark$ \\
\hline
\end{tabular}

and $2.47 \mathrm{~V}$, respectively. Finally, $\mathrm{PhS}_{2} \mathrm{Li}$ and $\mathrm{Li}_{2} \mathrm{~S}_{2}$ are reduced into PhSLi and $\mathrm{Li}_{2} \mathrm{~S}$ at an average voltage of $2.04 \mathrm{~V}$. The voltage prediction will be of great value in the research of $\mathrm{PhS}_{n} \mathrm{Ph}$ as cathodes for Li-S batteries.

In the whole discharge process, there is no $\mathrm{Li}_{2} \mathrm{~S}_{4}, \mathrm{Li}_{2} \mathrm{~S}_{6}, \mathrm{Li}_{2} \mathrm{~S}_{8}$. To compare the dissolution of $\mathrm{PhS}_{n} \mathrm{Li}$ and $\mathrm{Li}_{2} \mathrm{~S}_{n}(n=4,6,8)$ in the DOL/DME solvent, the dissolving free energies ${ }^{37}$ of them with the solvent effect of DOL/DME $(1: 1, \mathrm{v} / \mathrm{v})$ are calculated. As shown in Fig. $\mathrm{S} 1, \uparrow$ the dissolving free energies of $\mathrm{PhS}_{n} \mathrm{Li}(1 \leq n \leq 13)$ are almost above those of $\operatorname{Li}_{2} S_{n}(n=4,6,8)$ which result in shuttle effect. Therefore, the solubilities of $\mathrm{PhS}_{n} \mathrm{Li}(1 \leq n \leq 13)$ are lower and the shuttle effect causes by $\mathrm{PhS}_{n} \mathrm{Li}$ is much weaker than that by $\operatorname{Li}_{2} S_{n}(n=4,6,8)$. We take it that the excellent stability of longchain $\mathrm{PhS}_{n} \mathrm{Li}$ and the dissociation positions of $\mathrm{S}-\mathrm{S}$ bonds jointly contribute to such a result. Here, it can be considered that phenyl plays a certain role in fixing soluble polysulfide, preventing polysulfide from being dissolved into the electrolyte, which can greatly slow down the "shuttle effect". This is beneficial to improve coulomb efficiency and capacity attenuation, and achieve better cycle stability and energy efficiency in practical applications. Until now, there are some ways to eliminate the "shuttle effect" particularly: improve the electrolyte performance, ${ }^{38}$ recombine cathodes with organic polymers ${ }^{39}$ or porous materials ${ }^{\mathbf{4 0}}$ and so on. In comparison to these ways, the synthesis of $\mathrm{PhS}_{15} \mathrm{Ph}$ is more facile and available. So this class of cathode materials is of great research significance and potential for LSBs.

\section{Summary}

In conclusion, using the $a b$ initio density functional theory calculation, we have performed thorough theoretical studies for diphenyl polysulfides as cathode materials for LSBs. One goal is to increase the sulfur proportion in $\mathrm{PhS}_{n} \mathrm{Ph}$ compounds, more sulfur proportion means high specific capacity; the other goal is to overcome the "shuttle effect" challenge for the current LSBs, namely the dissolution of lithium polysulfide. Though the Gibbs free energy calculation and "alloy-like" diagram analysis, we found the $\mathrm{PhS}_{n} \mathrm{Ph}$ molecules are thermodynamically stable, and the $\mathrm{PhS}_{15} \mathrm{Ph}$ behave almost the same energy density as $\mathrm{S}_{8}, 2632 \mathrm{~W} \mathrm{~h} \mathrm{~kg}^{-1}$. By calculation the $\mathrm{BDE}$ of the $\mathrm{PhS}_{n} \mathrm{Ph}$ cathode, we found that only short-chain polysulfides generate in the discharge process, $\mathrm{PhS}_{n} \mathrm{Ph}$ prevents the formation of soluble long-chain intermediates that plague traditional sulfur cathodes. We hope that this work leads to further studies in experiment, which would make $\mathrm{PhS}_{n} \mathrm{Ph}$ a promising candidate for low-cost, eco-friendly, and intrinsically safe cathode materials for applications in rechargeable lithium batteries.

There are other aspects which we haven't discussed until now, most importantly, the volumetric capacity. One cannot get high volumetric capacity by using only one $\mathrm{PhS}_{n} \mathrm{Ph}$ molecule, a possible solution might include the use of $\mathrm{PhS}_{n} \mathrm{Ph}$ molecule to establish unit cell of $3 \mathrm{D}$ frameworks, ${ }^{\mathbf{4 1}}$ but poor conductivity is a very big defect. Recently, Se is introduced into $\mathrm{S}$ cathodes by forming Se-S bonds to modify the electronic and ionic conductivity and ultimately enhance cathode utilization in LSBs, ${ }^{\mathbf{4 2 , 4 3}}$ this is also the topic we need to study next.

\section{Conflicts of interest}

There are no conflicts to declare. 


\section{Acknowledgements}

JBW was supported by the National Natural Science Foundation of China (No. 11047164), the Shanghai College Foundation for Excellent Young Teachers of China (No. gjd10023) and the Academic Program of Shanghai Municipal Education Commission (No. 11XK11 and 2011X34).

\section{References}

1 A. Manthiram, S. H. Chung and C. X. Zu, Adv. Mater., 2015, 27, 1980-2006.

2 Y. Diao, K. Xie, S. Z. Xiong and X. B. Hong, J. Power Sources, 2013, 235, 181-186.

3 W. Chen, T. Lei, C. Wu, M. Deng, C. Gong, K. Hu, Y. Ma, L. Dai, W. Lv, W. He, X. Liu, J. Xiong and C. Yan, Adv. Energy Mater., 2018, 8, 1702348.

4 Y. B. He, Y. Qiao and H. S. Zhou, Dalton Trans., 2018, 47, 6881-6887.

5 K. Yang, S. N. Zhang, D. M. Han, M. Xiao, S. J. Wang and Y. Z. Meng, Prog. Chem., 2018, 30, 1942-1959.

6 V. Knap, D. I. Stroe, M. Swierczynski, R. Teodorescu and E. Schaltz, J. Electrochem. Soc., 2016, 163, A911-A916.

7 A. Fotouhi, D. Auger, L. O'Neill, T. Cleaver and S. Walus, Energies, 2017, 10, 1937.

8 A. Manthiram, Y. Z. Fu and Y. S. Su, Acc. Chem. Res., 2013, 46, 1125-1134.

9 W. Chen, T. Lei, T. Qian, W. Lv, W. He, C. Wu, X. Liu, J. Liu, B. Chen, C. Yan and J. Xiong, Adv. Energy Mater., 2018, 8, 1702889.

10 T. Lei, W. Chen, W. Lv, J. Huang, J. Zhu, J. Chu, C. Yan, C. Wu, Y. Yan, W. He, J. Xiong, Y. Li, C. Yan, J. B. Goodenough and X. Duan, Joule, 2019, 3, 2091-2104.

11 A. Bhargav, S. V. Patil and Y. Fu, Sustainable Energy Fuels, 2017, 1, 1007-1012.

12 X. Liang, C. Hart, Q. Pang, A. Garsuch, T. Weiss and L. F. Nazar, Nat. Commun., 2015, 6, 8.

13 T.-G. Jeong, Y.-S. Lee, B. W. Cho, Y.-T. Kim, H.-G. Jung and K. Y. Chung, J. Alloys Compd., 2018, 742, 868-876.

14 J. Zheng, G. Ji, X. Fan, J. Chen, Q. Li, H. Wang, Y. Yang, K. C. DeMella, S. R. Raghavan and C. Wang, Adv. Energy Mater., 2019, 16, 1803774.

15 T. Lei, W. Chen, Y. Hu, W. Lv, X. Lv, Y. Yan, J. Huang, Y. Jiao, J. Chu, C. Yan, C. Wu, Q. Li, W. He and J. Xiong, Adv. Energy Mater., 2018, 8, 1802441.

16 M. Wu, A. Bhargav, Y. Cui, A. Siegel, M. Agarwal, Y. Ma and Y. Z. Fu, ACS Energy Lett., 2016, 1, 1221-1226.

17 A. Bhargav, M. E. Bell, J. Karty, Y. Cui and Y. Fu, ACS Appl. Mater. Interfaces, 2018, 10, 21084-21090.

18 W. Chen, T. Lei, W. Lv, Y. Hu, Y. Yan, Y. Jiao, W. He, Z. Li, C. Yan and J. Xiong, Adv. Mater., 2018, 40, e1804084.
19 Y. C. Qiu, W. F. Li, W. Zhao, G. Z. Li, Y. Hou, M. N. Liu, L. S. Zhou, F. M. Ye, H. F. Li, Z. H. Wei, S. H. Yang, W. H. Duan, Y. F. Ye, J. H. Guo and Y. G. Zhang, Nano Lett., 2014, 14, 4821-4827.

20 P. Adelhelm, P. Hartmann, C. L. Bender, M. Busche, C. Eufinger and J. Janek, Beilstein J. Nanotechnol., 2015, 6, 1016-1055.

21 D. Larcher and J. M. Tarascon, Nat. Chem., 2015, 7, 19-29.

22 N. Nitta, F. X. Wu, J. T. Lee and G. Yushin, Mater. Today, 2015, 18, 252-264.

23 J. B. Wu and L. W. Wang, J. Mater. Chem. A, 2018, 6, 29842994.

24 R. Steudel, Chem. Rev., 2002, 102, 3905-3945.

25 H. J. Peng, J. Q. Huang, X. B. Cheng and Q. Zhang, Adv. Energy Mater., 2017, 7, 54.

26 S. S. Zhang, J. Power Sources, 2013, 231, 153-162.

27 L. J. Wang, T. R. Zhang, S. Q. Yang, F. Y. Cheng, J. Liang and J. Chen, J. Energy Chem., 2013, 22, 72-77.

28 J. Hassoun, Y.-K. Sun and B. Scrosati, J. Power Sources, 2011, 196, 343-348.

29 M. Yao, H. Ando and T. Kiyobayashi, Energy Procedia, 2016, 89, 222-230.

30 Z. Lan, M. Chen, X. Xu, C. Xiao, F. Wang, Y. Wang, Y. Lu, Y. Jiang and J. Jiang, J. Alloys Compd., 2017, 701, 875-881.

31 X. L. Ji and L. F. Nazar, J. Mater. Chem., 2010, 20, 9821-9826.

32 X. Liu, B. K. Li, L. Yao, P. B. Wang, X. H. Kong and Y. F. Zhang, J. Nanosci. Nanotechnol., 2019, 19, 4052-4057.

33 B. Kalimuthu, N. Muralidharan and K. Nallathamby, J. Alloys Compd., 2019, 780, 177-185.

34 J. M. Hudzik and J. W. Bozzelli, J. Phys. Chem. A, 2012, 116, 5707-5722.

35 D. Julian, in 3rd International Seminar on Chemistry 2014, ed. H. Hayashi, R. Read and K. Awang, Elsevier Science Bv, Amsterdam, 2015, vol. 17, pp. 99-105.

36 C. G.-F. M. J. Bausch and R. Gostowski, Energy Fuels, 1991, 3, 419-423.

37 R. F. Ribeiro, A. V. Marenich, C. J. Cramer and D. G. Truhlar, J. Phys. Chem. B, 2011, 115, 14556-14562.

38 L. Wang, Y. Ye, N. Chen, Y. Huang, L. Li, F. Wu and R. Chen, Adv. Funct. Mater., 2018, 28, 1800919.

39 J. Z. Zhen Li, Y. Lu and X. W. Lou, Sci. Adv., 2018, 6, eaat1687. 40 G. Ma, Z. Wen, J. Jin, Y. Lu, X. Wu, M. Wu and C. Chen, J. Mater. Chem. A, 2014, 2, 10350-10354.

41 W. Guo, A. Bhargav, J. D. Ackerson, Y. Cui, Y. Ma and Y. Fu, Chem. Commun., 2018, 54, 8873-8876.

42 J. Zhou, T. Qian, N. Xu, M. Wang, X. Ni, X. Liu, X. Shen and C. Yan, Adv. Mater., 2017, 33, 1701294.

43 X. Li, J. Liang, J. Luo, C. Wang, X. Li, Q. Sun, R. Li, L. Zhang, R. Yang, S. Lu, H. Huang and X. Sun, Adv. Mater., 2019, 17, e1808100. 